\title{
DA OMISSÃO INCONSTITUCIONAL PARCIAL AO "ESTADO DE COISAS INCONSTITUCIONAL": REFLEXÕES A PARTIR DA DECISÃO DO STF NA RECLAMAÇÃO 4.374/PE
}

Vânia Petermann ${ }^{1}$

\section{RESUMO}

Sob a perspectiva do ativismo judicial dialógico - intervenção legítima do Poder Judiciário na definição de políticas públicas quando realizada em diálogo com os demais Poderes -, discutese, neste trabalho, a figura jurisprudencial do estado de coisas constitucional. Após percorrer um itinerário do seu aparecimento como técnica decisória na Colômbia e da sua consolidação nas cortes constitucionais latino-americanas, pretende-se discutir sua possível adequação ao caso discutido na Reclamação 4.374/PE, julgada pelo Supremo Tribunal Federal em 2013 a fim de verificar a (in)adequabilidade dessa decisão frente àquela categoria jurídica. Trata-se de uma ampliação da aplicação desse conceito na jurisprudência brasileira a uma temática em que ainda não foi contemplado: a assistência social e o mínimo existencial.

Palavras-chave: Estado de coisas inconstitucional. Direitos fundamentais. Assistência social.

FROM THE PARTIAL UNCONSTITUTIONAL OMISSION TO THE "UNCONSTITUTIONAL STATE OF THINGS": REFLECTIONS FROM THE STF DECISION IN COMPLAINT 4.374 / PE

\section{ABSTRACT}

Under the perspective of the dialogic judicial activism - a legitimate intervention of the Judiciary in the definition of public policies when made in dialogue with the other powers -, the present article discusses the jurisprudential figure of the unconstitutional state of things. After describing its itinerary since its emergence as a technic of decision in Colombia and its consolidation in other constitutional courts of Latin America, the objective is to discuss the possible adequacy of this concept to the case debated on the Reclamation 4.374/PE, judged by the Brazilian Federal Supreme Court in 2013 with the aim of verifying the (un)suitability of this decision in front of that juridical category. Succinctly, it's a tentative of expanding the application of this concept in the Brazilian jurisprudence at a matter in which it has not been discussed yet: the social assistance and the existential minimum.

Keywords: Unconstitutional state of things. Fundamental Rights. Social assistance.

Data de submissão: 02/06/2019

Data de aprovação: 04/10/2019

Double Blind Review Process

DOI: http://dx.doi.org/10.21902/rctjsc.v7i1.339

\footnotetext{
${ }^{1}$ Doutoranda pela UNIVALI - Universidade do Vale do Itajá́, Brasil, e pela Universidade da Perugia Itália; Mestre em Ciências Jurídicas pela UNIVALI - Universidade do Vale do Itajaí. Juíza de direito do Juizado Especial da Uuniversidade Federal de Santa Catarina. Diretora Acadêmico/Pedagógica e Formadora na Academia Judicial do Tribunal de Justiça de Santa Catarina, Brasil. E-mail vaniapetermann@gmail.com.
} 


\section{INTRODUÇÃO}

El mundo se divide, sobre todo, entre indignos e indignados, y ya sabrá cada quien de qué lado quiere o puede estar (Eduardo Galeano).

Nos últimos anos, o Supremo Tribunal Federal passou a ocupar, com alta frequência, lugar de destaque na imprensa cotidiana pelas decisões de enorme visibilidade e projeção política e social sobre temas centrais e polêmicos, como o reconhecimento da união homoafetiva em 2011 (ADI 4277 e ADPF 132), a permissão do aborto de fetos anencéfalos em 2012 (ADPF 54), o julgamento da Ação Penal 470, mais conhecida como "mensalão", concluído em 2014, e mais recentemente as decisões que envolvem a operação Lava-Jato.

Esta ampliação da cobertura midiática da corte e sua consequente projeção institucional têm sido acompanhadas por um grande crescimento de pesquisas acadêmicas sobre o tribunal. Neste espaço, cabe destacar algumas iniciativas que serviram como fonte para a presente pesquisa, como o "Supremo em Pauta", "Supremo em Números"3 "STF em Foco" 4 e a plataforma virtual "Supremo em Ação"5.

Um dos temas de maior repercussão acadêmica entorno desse cenário, por óbvio, foi a discussão sobre o ativismo judicial. A doutrina norte-americana, berço deste tema e do termo judicial activism ${ }^{6}$ - já se debruça sobre essa problemática há mais de dois séculos, mas no Brasil

\footnotetext{
2 Projeto permanente da Faculdade de Direito de São Paulo da Fundação Getúlio Vargas, consiste em um programa de acompanhamento sistemático das decisões do STF, como uma tentativa de compreender e avaliar os parâmetros normativos e hermenêuticos sobre os quais se baseiam as decisões da corte, procurando delinear a lógica que orienta a composição da sua agenda e gerando um banco de dados de informações públicas. Para mais informações, conferir o endereço eletrônico institucional do projeto: FUNDAÇÃO GETÚLIO VARGAS. Supremo em pauta. 2017.

${ }^{3}$ Projeto permanente da Faculdade de Direito do Rio de Janeiro da Fundação Getúlio Vargas, busca aliar habilidades jurídicas e informáticas para reunir dados inéditos sobre o Supremo Tribunal Federal, os quais são filtrados em razão do que revelam sobre aspectos centrais do que o Supremo decide, quando e como. Para mais informações, conferir o endereço eletrônico institucional do projeto: FUNDAÇÃO GETÚLIO VARGAS. Supremo em números. 2017.

${ }^{4}$ Iniciativa da organização não governamental internacional Conectas, instituição voltada à efetivação dos direitos humanos e do Estado Democrático de Direito no Sul Global, que criou um banco de dados de processos, análises e materiais multimídia sobre as decisões do Supremo Tribunal Federal em matéria de direitos humanos. O projeto é derivado da notável participação da organização no debate constitucional, que já apresentou mais de 40 amicus curiae perante o STF. Para mais informações, conferir o endereço eletrônico institucional do projeto: CONECTAS. STF em foco. 2017.

${ }^{5}$ Esta ferramenta digital, disponível na Internet e também na forma de aplicativo, foi criada pelo Conselho Nacional de Justiça com o objetivo de conferir maior transparência às atividades do Supremo. Para tanto, fornece informações detalhadas sobre a produção de sentenças e o volume de processos judiciais sob responsabilidade de cada um dos atuais ministros do STF, inclusive as ações que ainda dependem de uma decisão. Para mais informações, conferir o endereço eletrônico institucional do projeto: CONSELHO NACIONAL DE JUSTIÇA. Supremo em Ação. 2017.

${ }^{6}$ Para um panorama bem delineado sobre as origens desse debate, cfr. KMIEC, Keenan D. The Origin and Current Meaning of "Judicial Activism". California Law Review, v. 92, n. 5, 2004, p. 1441-1477.
}

Rev. do Cejur: Prestação Jurisdicional, Florianópolis v.7 n.1, p. 219-237, Janeiro-Dezembro. 2019. 
a discussão ganhou novo fôlego a partir da promulgação da Constituição da República Federativa do Brasil de 1988, a qual atribuiu poderes mais robustos à Suprema Corte do que todas as suas predecessoras, seja criando um novo modelo de controle judicial de constitucionalidade, seja alargando o substrato de direitos fundamentais protegidos pelo texto constitucional $^{7}$. Por certo, essa proeminência atribuída ao STF não foi acolhida de forma pacífica pela doutrina brasileira e intensos debates foram travados entorno da sua (i)legitimidade ${ }^{8}$.

Para o presente trabalho, elegeu-se como marco teórico a obra de Carlos Alexandre de Azevedo Campo, intitulada Dimensões do ativismo Judicial do $S T F^{9}$, para a qual o comportamento ativista de juízes e cortes pode ser influenciado e justificado por diferentes fatores de natureza política, social e jurídico-cultural, bem como pode se manifestar por diferentes dimensões decisórias. Sob essa perspectiva, o ativismo judicial não pode ser considerado aprioristicamente ilegítimo, pois isso depende dos diferentes fatores envolvidos e da dimensão decisória manifestada. Desse modo, apenas a dimensão antidialógica, quando a corte se recusa a dialogar com os demais poderes e declara a "supremacia judicial", deve ser considerada uma manifestação judicial ilegítima em qualquer hipótese.

Como corolário desse ponto de vista, este artigo pretende enfatizar a figura do estado de coisas inconstitucional (ECI) no Brasil - criada pela Corte Constitucional colombiana como um exercício concreto de ativismo judicial cabível diante de cenários de reiterados comportamentos políticos omissivos e de sistemáticas violações de direitos fundamentais apresentado à comunidade acadêmica nacional pelo mesmo autor em sua tese de doutorado, depois transformada em livro ${ }^{10}$. O ECI, portanto, vem aqui entendido como técnica de decisão voltada à tutela de direitos fundamentais, principalmente os sociais, por meio da intervenção judicial no âmbito das políticas públicas. Uma corte, ao reconhecer a existência desse estado,

\footnotetext{
${ }^{7}$ MENDES, Conrado Hübner. Direitos fundamentais, separação de poderes e deliberação. Saraiva: São Paulo, 2011. p. 12.

${ }^{8}$ Para um quadro do estado da arte da discussão sobre ativismo judicial no Brasil, cfr., especialmente o segundo capítulo: TASSINARI, Clarissa. Ativismo Judicial: Uma análise da atuação do Judiciário nas experiências brasileira e norte-americana. 2012. 139 f. Dissertação (Mestrado) - Curso de Direito, Universidade do Vale do Rio Sinos, São Leopoldo, 2012.

${ }^{9}$ CAMPOS, Carlos Alexandre de Azevedo. Dimensões do ativismo judicial do STF. Rio de janeiro: Forense, 2014.

${ }^{10}$ A Tese intitulada Da Inconstitucionalidade por Omissão ao "Estado de Coisas Constitucional" defendida na UERJ em 2015 transformou-se, um ano depois, no livro intitulado Estado de Coisas Constitucional. Neste trabalho utilizou-se a versão mais recente. CAMPOS, Carlos Alexandre de Azevedo. Estado de coisas Inconstitucional. Salvador: JusPodium, 2016.
}

Rev. do Cejur: Prestação Jurisdicional, Florianópolis v.7 n.1, p. 219-237, Janeiro-Dezembro. 2019. 
avoca para si a legitimidade de interferir na agenda política com vistas a minimizar quadros de violação massiva e sistemática de direitos fundamentais.

O objetivo, em síntese, é confrontar esta categoria com a decisão do Supremo Tribunal Federal de 2013 na Reclamação 4.374/PE, verificando se, neste caso, o entendimento da Corte se justifica perante a lógica da técnica decisória do estado de coisas inconstitucional. A escolha deste caso, concernente à previsão constitucional de assistência social aos portadores de deficiência e idosos hipossuficientes, como paradigma do trabalho, justifica-se por se tratar de matéria que afeta direitos fundamentais básicos de uma camada social notoriamente fragilizada, para a qual a atuação judicial demonstrou-se fundamental na definição de uma política pública. Pretende-se, portanto, apresentar o caso e examinar os fundamentos da decisão partindo da categoria teórica acima definida, verificando a sua (in)adequabilidade frente à natureza e magnitude da demanda.

O método eleito para a produção deste estudo é o indutivo, a coleta de dados se deu pelo método cartesiano, as técnicas de investigação utilizadas foram de pesquisas em obras disponíveis na rede mundial de computadores e em obras impressas.

\section{2 "ESTADO DE COSAS" INCONSTITUCIONAL: ORIGENS E DESENVOLVIMENTOS DE UM CONCEITO JURISPRUDENCIAL EM CONSTRUÇÃO}

A categoria jurídica "estado de coisas inconstitucional” foi concebida há duas décadas pela Corte Constitucional colombiana na sentença SU-559 ${ }^{11}$ de 6 de novembro de 1997. A decisão foi dada diante de demanda proposta por um grupo de professores dos municípios de María La Baja y Zambrano do estado de Bolívar, que ingressaram com ação de tutela de direitos previdenciários e de saúde contra as autoridades públicas municipais, que não haviam depositado suas parcelas de contribuição, em que pese aplicassem desconto mensal de 5\% no salário sob essa rubrica.

No caso em tela, a magistrada Clara Inés Vargas Hernández ${ }^{12}$ explica que a Corte Constitucional poderia ter se limitado a declarar a violação dos direitos subjetivos dos

\footnotetext{
${ }^{11}$ COLÔMBIA. Corte Constitucional. Sentencia Unificadora n ${ }^{\circ}$ 559. Relator: Eduardo Cifiuentes Muñoz. Diario Oficial. Bogotá, 5 nov. 1997.

${ }^{12}$ HERNÁNDEZ, Clara Inés Vargas. La Garantía de la dimensión objetiva de los derechos fundamentales y labor del juez constitucional colombiano em sede de acción de tutela: el llamado "estado de cosas inconstitucional". Revista del Centro de Estudios Constitucionales, Santiago, v. 1, n. 1, p. 203-228, 2003.
}

Rev. do Cejur: Prestação Jurisdicional, Florianópolis v.7 n.1, p. 219-237, Janeiro-Dezembro. 2019. 
demandantes devido à omissão na qual incorreram as autoridades municipais, explorando simplesmente a sua dimensão subjetiva. Entretanto, o juiz constitucional considerou necessário ingressar n esfera da garantia objetiva dos direitos fundamentais, isto é, no fundo do problema, examinando as cifras de afiliação ao Fundo Nacional de Prestações Sociais do Magistério, concluindo que o subsídio educativo que a Nação designa às entidades territoriais para o pagamento dos docentes era distribuído de forma muito desigual.

Sob esse pano de fundo reside - e aqui se pretende destacar - a dificuldade entre compreender os direitos fundamentais como simples direitos subjetivos ou ir além e concebêlos como princípios constitucionais que impõem deveres de atuação às autoridades públicas. Optando pela segunda posição, a Corte analisou, naquele caso, uma situação estrutural e a eficácia de algumas políticas públicas. Para proteger a dimensão objetiva dos direitos fundamentais, a Corte Constitucional colombiana tomou medida extrema e criou uma nova categoria ao reconhecer a vigência de um "estado de cosas" inconstitucional ${ }^{13}$.

Disso resultam algumas consequências processuais. Em primeiro lugar: a extensão dos efeitos da tutela do caso específico a demandas semelhantes. Isso porque, com a ordem cautelar, destinada a proteger os direitos fundamentais dos demandantes, a Corte declara a existência de uma situação estrutural que lesiona, de maneira permanente, o exercício dos direitos fundamentais de um número amplo, e em algumas ocasiões indeterminado, de pessoas que não instauraram a demanda. Daquela sentença, extrai-se:

La circunstancia de que el estado de cosas no solamente sirva de soporte causal de la lesión iusfundamental examinada, sino que, además, lo sea en relación con situaciones semejantes, no puede restringir el alcance del requerimiento que se formule ${ }^{14}$.

Em segundo lugar: a tutela apresenta um efeito preventivo geral ao apontar às autoridades públicas um dever de corrigir a situação de fato que a contraria a Constituição. Essa iniciativa consistiria, na definição do Ministro Relator, em um dever de colaborar de maneira harmônica com os demais órgãos do Estado para a realização de seus fins.

El deber de colaboración se torna imperativo si el remedio administrativo oportuno puede evitar la excesiva utilización de la acción de tutela. Los recursos con que cuenta la administración de justicia son escasos. Si instar al cumplimiento diligente de las obligaciones constitucionales que pesan sobre una determinada autoridad contribuye a reducir el número de causas

\footnotetext{
${ }^{13}$ Para um estudo aprofundado sobre as duas dimensões dos direitos fundamentais e a sua relação com o estado de coisas constitucional, cfr: MARTÍNEZ, Julián Tole. La teoria de la doble dimensión de los derechos fundamentales en Colombia.: El estado de cosas inconstitucionales, un ejemplo de su aplicación.. Cuestiones Constitucionales, Cidade do México, v. 15, n. 2, p.253-316, jun. 2006.

${ }^{14}$ COLÔMBIA. Corte Constitucional. Sentencia Unificadora $\mathrm{n}^{\circ}$ 559. p. 3
}

Rev. do Cejur: Prestação Jurisdicional, Florianópolis v.7 n.1, p. 219-237, Janeiro-Dezembro. 2019. 
constitucionales, que de otro modo inexorablemente se presentarían, dicha acción se erige también en medio legítimo a través del cual la Corte realiza su función de guardiana de la integridad de la Constitución y de la efectividad de sus mandatos ${ }^{15}$.

Desse modo percebe-se a diferença significativa entre o juiz entender que se encontra diante de uma simples violação ou ameaça a um direito fundamental e reconhecer que se trata de um "estado de cosias constitucional". Reconhecer esse quadro significa que o juiz não se limita a examinar o caso específico, sim contextualiza-o e insere-o em uma situação muito mais ampla e estrutural que é a causa profunda não apenas de uma lesão particular e concreta a direitos fundamentais, mas se reflete em outros casos semelhantes.

Por certo, tratando-se de um conceito jurisprudencial - ainda que possam ser identificadas suas raízes nos structural remedies dos Estados Unidos ${ }^{16}-$, foi reelaborado e aperfeiçoado pela própria Corte Constitucional colombiana em sentenças posteriores, bem como rediscutido e desenvolvido em outros países da América Latina ${ }^{17}$. Os requisitos originalmente elencados pela Corte colombiana para configurar este quadro originalmente eram dois:

El estado de cosas inconstitucional se predica de aquellas situaciones en las que (1) se presenta una repetida violación de derechos fundamentales de muchas personas - que pueden entonces recurrir a la acción de tutela para obtener la defensa de sus derechos y colmar así los despachos judiciales - y (2) cuando la causa de esa vulneración no es imputable únicamente a la autoridad demandada, sino que reposa en factores estructurales ${ }^{18}$.

Alguns anos depois, em uma manifestação mais consolidada dessa doutrina, novos requisitos foram estabelecidos, sendo a sistematização mais clara e objetiva dos seus pressupostos reproduzida a seguir:

Como factores o causas que producen la existencia de un estado de cosas inconstitucional, destacó los siguientes:

1) La vulneración masiva y generalizada de varios derechos constitucionales que afecta

\footnotetext{
${ }^{15}$ Ibidem.

${ }^{16}$ A Magistrada Clara Inés Vargas Hernández, em sentença de 2003, reconhece essa origem afirmando que: “Al respecto cabe señalar que la figura del estado de cosas inconstitucional parte de buscar una protección objetiva de los derechos fundamentales. En el derecho comparado, hunde sus raíces en una aguda controversia doctrinal y jurisprudencial que surgió, desde finales de los años cincuenta en los Estados Unidos, entre los defensores de la "political question doctrine" y aquellos partidarios de los "structural remedies". COLÔMBIA. Corte Constitucional. Sentencia T-1030. Relatora: Clara Inés Vargas Hernández. Diario Oficial. Bogotá, 30 out. 2003.

${ }^{17}$ Contreras, López e Villegas apontam a Argentina como o segundo país latino-americano a implementar a figura, seguida pelo Peru. Para um quadro aprofundado da difusão desse conceito, cfr: CONTRERAS, Edgar Hernán Fuentes; LÓPEZ, Beatriz Eugenia Suárez; VILLEGAS, Adriana Rincón. Facticidad y Constitución: la doctrina del estado de cosas inconstitucional en América Latina. Athenas, Conselheiro Lafaiete, v. 1, n. 2, p.49-75, jul. 2012.

${ }^{18}$ COLÔMBIA. Corte Constitucional. Sentencia Unificadora no 090/00. Relator: Eduardo Cifiuentes Muñoz. Diario Oficial. Bogotá, 2 fev. 2000.
}

Rev. do Cejur: Prestação Jurisdicional, Florianópolis v.7 n.1, p. 219-237, Janeiro-Dezembro. 2019. 
a un número significativo de personas.

2) La prolongada omisión de las autoridades en el cumplimiento de sus obligaciones para garantizar estos derechos.

3) La adopción de prácticas inconstitucionales, como la exigencia de incorporar la acción de tutela como parte del procedimiento para garantizar el derecho conculcado.

4) La no expedición de medidas legislativas, administrativas o presupuestales necesarias para evitar la vulneración de los derechos.

5) La existencia de un problema social cuya solución compromete la intervención de varias entidades, para la adopción mancomunada de un conjunto de medidas multisectoriales que... exige un nivel de recursos que demanda un esfuerzo presupuestal adicional importante.

6) Si todas las personas afectadas por el mismo problema acudieran a la acción de tutela para obtener la protección de sus derechos, se produciría una mayor congestión judicial $^{19}$.

Ao aprofundar o estudo doutrinário dessa categoria, Campos de Azevedo relembra o cuidado e parcimônia com que esse conceito deve ser aplicado, evitando-se excessos e a banalização do termo, tendo em vista que o seu reconhecimento implica em uma intervenção ativa do Poder Judiciário para transformar a realidade social. Por conta disso, o autor propõe nova sistematização, mais rígida e cautelosa, para identificação e afirmação do ECI, baseada em quatro pressupostos.

O primeiro deles consiste na cumulação de três aspectos: i) violação massiva e contínua (não bastando a mera proteção deficiente) ii) de direitos fundamentais variados (não a violação a quaisquer direitos ou a um direito em específico) que atinja iii) um número elevado e amplo de pessoas ${ }^{20}$.

O segundo deles é a omissão reiterada e persistente das autoridades públicas no cumprimento de suas obrigações de defesa e promoção dos direitos fundamentais, seja pela ausência de medidas legislativas ou administrativas. Para o autor, não configuraria a inércia de uma única autoridade pública, mas o funcionamento deficiente do Estado como um todo considerado, isto é, um mau funcionamento estrutural e histórico do Estado ${ }^{21}$.

$\mathrm{O}$ terceiro deles ${ }^{22}$ diz respeito às medidas necessárias para superar a inconstitucionalidade: o ECI se configura quando a solução do problema da violação de direitos passa pela expedição de políticas públicas não apenas por um órgão, mas por um conjunto deles. Por conta disso relaciona-se essa figura jurídica à figura do litígio estrutural ${ }^{23}$.

${ }^{19}$ COLÔMBIA. Corte Constitucional. Sentencia T-068/10. Relator: Ignacio Pretelt Chaljub. Diario Oficial. Bogotá, 4 fev. 2010.

${ }^{20}$ CAMPOS, Carlos Alexandre de Azevedo. Estado de coisas Inconstitucional, 2016, p. 180.

${ }^{21}$ Idem, p. 181.

${ }^{22}$ Idem, p. 183.

${ }^{23}$ Conflito que afeta um número amplo de pessoas, de entidades estatais e requer ordens de resolução complexa. Para uma ampla discussão desse conceito na América Latina, cfr: IGLESIAS, Edimer Leonardo Latorre et al. Rev. do Cejur: Prestação Jurisdicional, Florianópolis v.7 n.1, p. 219-237, Janeiro-Dezembro. 2019. 
$\mathrm{O}$ quarto ${ }^{24}$ e último diz respeito à potencialidade de um número elevado de afetados ingressarem com demandas judiciais semelhantes, ocasionando grave congestionamento da máquina judiciária. A Corte, portanto, busca resolver a situação de uma única vez, com uma intervenção mais ampla na realidade social.

Em um esforço de síntese final, Campos de Azevedo propõe uma definição do estado de coisas inconstitucional como

\begin{abstract}
a técnica de decisão por meio da qual as cortes e juízes constitucionais, quando rigorosamente identificam um quadro de violação massiva e sistemática de direitos fundamentais decorrente de falhas estruturais do Estado, declaram a absoluta contradição entre os comandos normativos constitucionais e a realidade social e expedem ordens estruturais dirigidas a instar um amplo conjunto de órgãos e autoridades a formularem e implementarem políticas públicas voltadas à superação dessa realidade inconstitucional ${ }^{25}$.
\end{abstract}

Definidos esses pressupostos, a próxima seção será dedicada ao estudo detalhado do caso definido neste trabalho como paradigma para discussão e aplicação dessa categoria na jurisprudência brasileira.

\title{
3 DA OMISSÃO INCONSTITUCIONAL AO ESTADO DE COISAS CONTRÁRIO À CONSTITUIÇÃO: A RECLAMAÇÃO 4.374/PE
}

Por ocasião do julgamento da Arguição de Descumprimento de Preceito Fundamental 347, com pedido de medida liminar, proposta pelo Partido Socialismo e Liberdade - PSOL, em que o Supremo Tribunal Federal brasileiro reconheceu a figura do "estado de coisas inconstitucional" relativamente ao sistema penitenciário brasileiro, determinando a adoção de providências estruturais em face de lesões a direitos fundamentais dos presos, muito se discutiu sobre essa técnica de decisão no Brasil.

Afinal, foi a primeira vez que essa tese foi debatida e acolhida pelo STF brasileiro, aplicando-se no direito pátrio a categoria desenhada pela Corte Constitucional da Colômbia e justificando-se a intervenção do Supremo em proteção da dignidade de grupos vulneráveis. Conforme voto do ministro Relator, Marco Aurélio Mendes de Farias Mello, esta manifestação se inseriria no exercício do papel contramajoritário próprio das cortes constitucionais ${ }^{26}$. A partir da técnica da declaração do "estado de coisas inconstitucional", poderia o juiz constitucional,

\footnotetext{
Litigio estructural en América Latina: Génesis y tendencias del constitucionalismo progressista. Bogotá: Universidad Sergio Arboleda, 2015.

${ }^{24}$ Idem, p. 185.

${ }^{25}$ CAMPOS, Carlos Alexandre de Azevedo. Estado de coisas Inconstitucional, 2016, p. 187.

${ }^{26}$ BRASIL. Supremo Tribunal Federal. Arguição de Descumprimento de Preceito Fundamental no 347 . Relator: Ministro Marco Aurélio. Brasília, DF, 09 de setembro de 2015. Diário da Justiça. Brasília, 09 set. 2015.
}

Rev. do Cejur: Prestação Jurisdicional, Florianópolis v.7 n.1, p. 219-237, Janeiro-Dezembro. 2019. 
então, impor aos Poderes Públicos a tomada de ações urgentes e necessárias ao afastamento das violações massivas de direitos fundamentais, assim como supervisionar a sua efetiva implementação.

Após essa data, o termo apareceu outras vezes em acórdãos do STF, mas sempre no que se refere ao sistema prisional brasileiro ${ }^{27}$. No presente trabalho, entretanto, propõe-se a análise dessa categoria em face de uma matéria diferente: o benefício assistencial de prestação continuada ao idoso e ao deficiente - previsto no art. 203, V, da CFRB - discutido na Reclamação 4.374/PE ${ }^{28}$.

Cumpre inicialmente esclarecer que a Reclamação foi ajuizada pelo Instituto Nacional do Seguro Social (INSS) contra decisão proferida pela Turma Recursal dos Juizados Especiais Federais do Estado de Pernambuco, a qual concedeu a interessado o benefício assistencial previsto no art. 203, inciso $\mathrm{V}$, da $\mathrm{CFRB}^{29}$, a partir da constatação de sua situação de hipossuficiência econômica, sem a observância do critério quantitativo de 1/4 do salário mínimo previsto no art. 20, $\S 3^{\circ}$, da Lei 8.742/93, a Lei Organização da Assistência Social (LOAS) ${ }^{30}$. A alegação do reclamante é de que houvera, no caso em comento, violação à decisão proferida na Ação Direta de Inconstitucionalidade 1.232/DF ${ }^{31}$, que declarou a constitucionalidade do $\S$ $3^{\circ}$ do art. 20 da LOAS, devendo, portanto, ser observado o critério objetivo da renda familiar per capita inferior a 1/4 do salário mínimo para atribuição do benefício.

\footnotetext{
${ }^{27}$ Em pesquisa de Jurisprudência no site do Supremo Tribunal Federal, com o parâmetro "estado de coisas inconstitucional", além da mencionada ADPF, encontram-se os acórdãos referentes ao Recurso Extraordinário 841526/RS, relatado pelo Ministro Luiz Fux e publicado em 1 de agosto de 2016 e o Habeas Corpus 118533/MS, relatado pela Min. Carmen Lúcia, publicado em 19 de setembro de 2016, em cujas fundamentações complementares de ambos o Ministro Ricardo Lewandoski faz referência à situação do sistema prisional brasileiro como um estado de coisas inconstitucional. Encontra-se, ainda, o acórdão referente ao Recurso Extraordinário 641320/RS, relatado pelo Ministro Gilmar Mendes e publicado em 11/05/2016, em cuja fundamentação complementar o Ministro Celso de Mello faz menção à mesma precariedade do sistema carcerário por meio dessa categoria jurídica. Todos eles, portanto, são posteriores ao julgamento da ADPF 347 e tratam do mesmo tema, para o qual o estado de coisas constitucional já havia sido declarado naquela oportunidade.

${ }^{28}$ BRASIL. Supremo Tribunal Federal. Reclamação 4.374. Relator: Ministro Gilmar Mendes. Brasília, DF, 18 de abril de 2013. Diário da Justiça, Brasília, 18 abr. de 2013

${ }^{29}$ Reproduz-se, aqui, a redação literal do dispositivo constitucional: "Art. 203. A assistência social será prestada a quem dela necessitar, independentemente de contribuição à seguridade social, e tem por objetivos: (...) V - a garantia de um salário mínimo de benefício mensal à pessoa portadora de deficiência e ao idoso que comprovem não possuir meios de prover à própria manutenção ou de tê-la provida por sua família, conforme dispuser a lei. BRASIL. Constituição (1988). Constituição da República Federativa do Brasil. Distrito Federal, SC, 5 out. 1988.

${ }^{30}$ Cita-se, também, a redação literal da lei infraconstitucional: Art. 20. O benefício de prestação continuada é a garantia de um salário-mínimo mensal à pessoa com deficiência e ao idoso com 65 (sessenta e cinco) anos ou mais que comprovem não possuir meios de prover a própria manutenção nem de tê-la provida por sua família. (...) § 3o Considera-se incapaz de prover a manutenção da pessoa com deficiência ou idosa a família cuja renda mensal per capita seja inferior a 1/4 (um quarto) do salário-mínimo". BRASIL. Dispõe sobre a organização da Assistência Social e dá outras providências.. Lei No 8.742, de 7 de Dezembro de 1993. Brasília, DF, 7 dez. 1993. ${ }^{31}$ BRASIL. Supremo Tribunal Federal. Ação Direta de Inconstitucionalidade n. 1232-1/DF. Relator: Ministro Nelson Jobim. Brasília, DF, 27 de agosto de 1998. Diário da Justiça. Brasília, 27 ago. 1998.
}

Rev. do Cejur: Prestação Jurisdicional, Florianópolis v.7 n.1, p. 219-237, Janeiro-Dezembro. 2019. 
Ao proferir seu voto, o ministro relator Gilmar Mendes reconhece, de fato, que a polêmica entorno deste dispositivo não era nova e já tinha sido, inclusive, apreciada pelo STF. Muito já se discutira sobre a pouca eficácia do art. 203, inciso V, da Constituição, deste antes da edição da Lei 7.742/93 - hipótese definida pela teoria constitucional como norma constitucional de eficácia limitada ${ }^{32}$-, a cuja promulgação tampouco se seguira grande êxito nesse sentido, pois a norma não a regulamentou de forma suficiente. Isso porque o estabelecimento do critério de mensuração da renda familiar per capita em um salário mínimo deixava fora do alcance do benefício social uma série de pessoas em situação de patente miserabilidade social simplesmente por ultrapassar, ainda que minimamente, esse requisito quantitativo. Apesar disso, a Corte manifestara-se no sentido de reconhecer a constitucionalidade do dispositivo quando da ADI 1.232-1 do DF pelo reconhecimento de que a lei, de fato, trazia um critério objetivo para a prestação assistencial do Estado, conforme impunha a Constituição.

Essa decisão do Tribunal, por certo, não pôs termo à controvérsia, pois o critério objetivo da lei estava muito distante da condição social concreta das famílias que necessitam de assistência social e tampouco se afinava com as políticas legislativas em matérias semelhantes que nos anos seguintes foram estabelecidas com critérios mais elásticos para a concessão de outros benefícios ${ }^{33}$. O maior problema, entretanto, da adoção de um critério número fixo e objetivo é que ele afasta potenciais beneficiários que necessitam do auxílio em virtude do não atendimento de um critério material mesmo que estejam, materialmente, em patente situação de miserabilidade social.

Levando-se isso conta é que o ministro Gilmar Mendes propôs a revisão da decisão anterior sobre a constitucionalidade do dispositivo admitindo a possibilidade de rever, no julgamento da reclamação, o acórdão que figurou como parâmetro da própria reclamação. Para o relator, a medida se justificativa tendo em vista a mudança das circunstâncias fáticas e da alteração das concepções jurídicas dominantes, de modo que, cabia, no caso em tela, a revisão da ADI 1.232 e novo juízo sobre a constitucionalidade do $§ 3^{\circ}$ do art. 20 da Lei 8.742/1993 ${ }^{34}$.

\footnotetext{
${ }^{32}$ Sobre o tema, cfr. a consagrada obra: SILVA, José Afonso. Aplicabilidade das Normas Constitucionais. 3. ed., revista atualizada e ampliada. São Paulo : Malheiros, 1998.

${ }^{33}$ Basta mencionar aqui, a título de exemplo, a Lei 10.836/2004, que criou o Bolsa Família; a Lei 10.689/2003, que instituiu o Programa Nacional de Acesso à Alimentação; a Lei 10.219/01, que criou o Bolsa Escola; dentre outros Programas que fixaram o valor de $1 / 2$ salário mínimo como referência para a aferição da renda familiar per capita.

${ }^{34}$ BRASIL. Supremo Tribunal Federal. Reclamação 4.374. 2013, p. 24.
}

Rev. do Cejur: Prestação Jurisdicional, Florianópolis v.7 n.1, p. 219-237, Janeiro-Dezembro. 2019. 
Considerando, então, a insuficiência do critério de 1/4 do salário mínimo utilizado pela LOAS e da sua omissão inconstitucional, portanto, originária, desde a sua promulgação, e além disso a inconstitucionalidade superveniente desse parâmetro, tendo em vista as leis posteriores que o tornaram ainda mais defasado, o ministro Gilmar mendes propôs que fosse i) julgada improcedente a Reclamação; ii) declarado inconstitucional o art. 20, § $3^{\circ}$ da Lei 8.742/1993, mas sem pronúncia de nulidade, iii) mantendo sua vigência até 31 de dezembro de 2014 . O relator considerou este um prazo razoável para que os órgãos técnicos e legislativos implementassem novos critérios para a concessão do benefício assistencial ${ }^{35}$.

Após a discussão no plenário, a Reclamação de fato foi julgada improcedente, mas foi declarada sua inconstitucionalidade parcial, sem pronúncia de nulidade e tampouco sem um prazo às autoridades competentes para adequação.

Delineado um panorama do caso e apresentada a pronúncia da Corte, parte-se à discussão, na próxima seção, sobre a (in)adequabilidade da decisão final ante ao quadro de violação de direitos fundamentais exposto e ao possível reconhecimento da figura do "estado de coisas inconstitucional" no caso em tela.

\section{ASSISTÊNCIA SOCIAL COMO DIREITO FUNDAMENTAL AO MÍNIMO EXISTENCIAL E A PROIBIÇÃO DE PROTEÇÃO INSUFICIENTE: O PANO DE FUNDO DO ESTADO DE COISAS INCONSTITUCIONAL}

Nesta seção, antes de adentrar no mérito da discussão quanto à configuração do estado de coisas inconstitucional no presente caso, cumpre retomar alguns conceitos do ponto de vista da teoria constitucional. A omissão normativa inconstitucional está prevista no artigo $103, \S 2^{\circ}$ da Carta da República como a "medida" - do Poder Executivo ou Legislativo - inapta a dar efetividade a determinada norma constitucional ${ }^{36}$, medida esta, portanto, que pode ser de competência tanto do legislador como de órgão administrativo. Para a doutrina tradicional clássica - utiliza-se aqui, de pleno direito, como paradigma a obra de José Joaquim Gomes Canotilho, a omissão em sentido jurídico-constitucional se verifica quando o legislador não faz

\footnotetext{
${ }^{35}$ Idem, p. 42.

${ }^{36}$ Reproduz-se, aqui, a íntegra do dispositivo constitucional: “Art. 103 (...) $\S 2^{\circ}$ Declarada a inconstitucionalidade por omissão de medida para tornar efetiva norma constitucional, será dada ciência ao Poder competente para a adoção das providências necessárias e, em se tratando de órgão administrativo, para fazê-lo em trinta dias". RASIL. Constituição (1988). Constituição da República Federativa do Brasil.
}

Rev. do Cejur: Prestação Jurisdicional, Florianópolis v.7 n.1, p. 219-237, Janeiro-Dezembro. 2019. 
aquilo a que estava constitucionalmente obrigado, isto é, não adota as medidas legislativas cabíveis para concretizar uma norma constitucional ${ }^{37}$.

O autor admite, também, que o conceito jurídico-constitucional de omissão é compatível com omissões legislativas parciais ou omissões relativas, isto é, omissões derivadas de atos legislativos voltados a concretizar normas constitucionais que favorecem certos grupos ou situações, esquecendo outros que preenchem os mesmos pressupostos de fato ${ }^{38}$.

Importante destacar, ainda, a sua posição no que se refere à admissibilidade de sentenças de "conteúdo intermédio", isto é, dentre as quais se insere a "simples declaração da incompatibilidade da norma com a constituição sem as consequências jurídicas da nulidade”. Em seu entendimento, não há cobertura constitucional para esse tipo de sentença quando ela implica em efeitos ainda mais restritos do que os da anulabilidade com eficácia ex nunc. A não atribuição dos efeitos da nulidade não pode significar, no seu ponto de vista, na sobrevivência e aplicação da norma considerada inconstitucional, tampouco poderiam os inconvenientes de lacunas legislativas se sobreporem aos riscos da violação ao princípio da constitucionalidade dos actos normativos ${ }^{39}$.

Retomando o conceito de estado de coisas constitucional, na já citada obra dedicada ao tema de Campos de Azevedo o autor propõe uma ampliação da noção de omissão constitucional, revisitando a visão tradicional e chamando atenção para critérios de ordem material a fim de que os direitos fundamentais deixem de ser, em seus termos, "direitos de papel" e recebam proteção e promoção estatal, principalmente a legislativa. Para tanto, o autor propõe que a atuação judicial, ante a inércia normativa, não deva se limitar à analise do descumprimento de um enunciado normativo determinada espécie de preceito constitucional (as normas constitucionais não exequíveis por si mesmas", mas justifica-se ante qualquer quadro real e atual de tutela estatal deficiente de direitos fundamentais, inclusive as normas consideradas "autoaplicáveis"40.

O autor também admite a possibilidade de que leis e iniciativas administrativas, ao tentarem dar cumprimento a comandos legais em favor da realização de direitos constitucionais, apresentem resultado pífio, demonstrando-se insuficientes na proteção estatal. A omissão, desse modo, não seria por conta da inexistência de uma lei e sim da ausência de estrutura apta a tornar

${ }^{37}$ CANOTILHO, José Joaquim Gomes. Direito Constitucional e Teoria da Constituição. $7^{\text {a }}$ ed. Coimbra: Alamedina, 1997. p. 1020. p. 1033.

${ }^{38}$ Idem, p. 1035.

${ }^{39}$ Idem, p. 1018.

${ }^{40}$ CAMPOS, Carlos Alexandre de Azevedo. Estado de coisas Inconstitucional, 2016, p. 56-57. Rev. do Cejur: Prestação Jurisdicional, Florianópolis v.7 n.1, p. 219-237, Janeiro-Dezembro. 2019. 
realidade os comandos legais, de modo que a norma não se concretiza plenamente. Tal situação, quando repetida, demonstra a ausência de capacidade institucional e disposição política do Legislativo e do Executivo para proteção completa de direitos fundamentais, em um quadro de profundas falhas estruturais. Quando esse quadro normativo se torna extremo, legitimam-se, então, medidas ativistas por parte do judiciário. "Configurada uma realidade massiva e sistemática violação de direitos fundamentais, decorrente da deficiência institucional e estrutural do Estado ou de bloqueios políticos, passa-se da inconstitucionalidade por omissão ao estado de coisas inconstitucional (ECI)" ${ }^{\prime 1}$.

A grande questão que aqui se coloca, portanto, é perceber se o caso em se tela se trata apenas de uma omissão inconstitucional ou de um verdadeiro quadro de estado de coisas inconstitucional. Como já explicitado na seção 2 deste artigo, na síntese elaborada por Carlos Campos, quatro são os requisitos cumulativos para a constatação do Estado de Coisas Inconstitucional: i) afronta generalizada de direitos e garantias fundamentais de um número significativo de pessoas; ii) quando se verifica que existe "falha estatal estrutural", ou seja, a inabilidade administrativa, legislativa, orçamentária e até mesmo judicial em garantir a efetivação de direitos fundamentais; iii) quando o problema é complexo, não envolve um caso particular e desafia a atuação de diferentes esferas estatais, sendo o remédio igualmente complexo, pois se dirigirá a uma pluralidade de órgãos e requer a implantação de novas políticas públicas; por fim, iv) a potencialidade de que um número elevado de interessados ingressarem com demandas judiciais semelhantes. No caso em tela, acredita-se que todos estes requisitos estão configurados cumulativamente, nos termos que seguem.

Em primeiro lugar, é necessário retomar o conceito de "mínimo existencial”, nos termos propostos por Ricardo Lobo, o qual, apesar de não estar contemplado por dicção normativa específica, está compreendido em diversos princípios constitucionais, como o princípio da igualdade - que assegura a proteção contra a pobreza absoluta -, o respeito à dignidade humana, a cláusula do Estado Social de Direito e em diversas outras classificações constitucionais relacionadas aos direitos fundamentais ${ }^{42}$. Justamente visando fornecer as condições mínimas para uma existência com dignidade é que foi consagrado o direito à assistência social aos que dela precisarem (art. 203, CFRB/1988). Esse amparo econômico está voltado a fornecer as bases mínimas para a vida com dignidade e fuga da pobreza. Para tanto,

\footnotetext{
${ }^{41}$ Ibidem, p. 58.

${ }^{42}$ TORRES, Ricardo Lobo. A metamorfose dos direitos sociais em mínimo existencial. In: SARLET, Ingo Wolfgang. Direitos Fundamentais Sociais: estudos de direito constitucional, internacional e comparado. Rio de Janeiro: Renovar, 2003, p. 32.
}

Rev. do Cejur: Prestação Jurisdicional, Florianópolis v.7 n.1, p. 219-237, Janeiro-Dezembro. 2019. 
são necessárias prestações materiais a serem oferecidas pelo Estado àqueles que não detêm condições próprias para prover a própria manutenção ou não tê-la provida pela sua família, com especial atenção, no caso em tela, aos idosos e pessoas com deficiência. Sendo assim, a eleição de um critério fixo e objetivo, que não dê conta de contemplar todas as pessoas que não atingem o mínimo existencial para a vida com dignidade, é uma violação a uma série de direitos fundamentais que dele decorrem.

Em segundo lugar, detecta-se no caso em tela uma falha estrutural, de responsabilidade do legislador - ao estabelecer um critério de proteção insuficiente - e das entidades administrativas que tampouco levam em consideração a situação de miserabilidade social concreta dos demandantes do benefício. O critério escolhido pelo legislador para auferir a pobreza, embora objetivo, não dá concretude à Constituição, pois fixa apenas no parâmetro "renda per capita", desconsiderando outros elementos do mundo dos fatos que são relevantes para constituir um quadro de hipossuficiência econômica. Desse modo, o legislador viola o princípio da proibição de proteção insuficiente ${ }^{43}$, o que constitui não apenas uma omissão parcial, mas uma inconstitucionalidade plena, à medida que o estabelecimento de um critério objetivo é mais nocivo ao deixar diversas pessoas alijadas do benefício do que a ausência de um parâmetro fixo, que permitisse a comprovação, em cada caso específico, da situação de miserabilidade.

Em terceiro lugar, o problema envolve solução complexa e conjunta de diversas instituições públicas. Por um lado, é necessária a edição de nova medida legislativa, voltada a estabelecer novo parâmetro para concessão do benefício, além do reconhecimento de outros meios de prova da condição de miserabilidade social que a mera aferição numérica da renda per capita. Além disso, compreende-se que a medida também passa pela atuação de Programas do Ministério do Desenvolvimento Social (Secretaria Nacional de Assistência Social, Departamento de Benefícios Assistenciais) e depende da expectativa orçamentária do Instituto Nacional do Seguro Social, de modo que, é necessária, portanto, o envolvimento coletivo de todos esses órgãos para a concretização da medida e dissolução do quadro de inconstitucionalidade.

\footnotetext{
${ }^{43}$ Este princípio foi desenvolvido originalmente pela jurisprudência do Tribunal Constitucional Federal Alemão, a partir da década de 50, sob o termo "Untermassverbot". Esse conceito aparece pela primeira vez em um julgamento do Supremo Tribunal Federal brasileiro em 2006, tomando como válida a premissa de que a Constituição Federal não tem apenas proposições de abstenção do Poder Público em face do indivíduo, mas traz também verdadeiros mandados constitucionais para atender ao dever de proteção. Para mais informações sobre a origem e conceito do instituto, cfr: BROOCKE, Alexandre Moreira van Der. A proibição de proteção deficiente e a inconstitucionalidade do artigo 20 da lei n. 8.429/1991. Revista da Ajuris: Associação dos Juízes do Rio Grande do Sul, Porto Alegre, v. 40, n. 129, p.13-136, 2013.
} 
Por fim, atendendo o quarto e último critério, percebe-se que diversas famílias que se encontram em situação de miserabilidade social estariam aptas a ingressar com ações semelhantes para requerer o benefício social, considerando-se, apenas a título ilustrativo, a Projeção de quantitativo de beneficiários potenciais do benefício na população brasileira conforme estudos do IPEA/2010 ${ }^{44}$. Segundo essa estimativa, se o critério da LOAS passasse de 1/4 do salário mínimo para metade dele, o número de potenciais beneficiários com deficiência aumentaria de 1.861.549 para 4.081.634 e de pessoas idosas se elevaria de 1.962.665 para 3.792.270. Recorre-se a essa estimativa numérica apenas para ilustrar numericamente essa defasagem, mas o objetivo, aqui, é levar em conta que a situação de miserabilidade social pode ser provada e constatada não apenas por meio de critérios numéricos, mas sim pela condição social concreta do demandante.

Por todos esses motivos, compreende-se que a situação fática que aparece como pano de fundo da Reclamação 4.374/PE, enseja o reconhecimento da existência de um estado de coisas inconstitucional, tendo em vista a ineficiência e insuficiência das políticas públicas legislativas e administrativas de assistência social a famílias que se encontram em situação de miserabilidade social e necessitam do benefício, mas não se encaixam no critério objetivo da LOAS. Disso decorre, portanto, não somente a declaração de inconstitucionalidade do dispositivo, mas a necessidade de adoção, por parte das instituições responsáveis, de medidas legislativas e administrativas concretas para reverter esse quadro.

\section{CONSIDERAÇÕES FINAIS}

Após traçar o itinerário de consolidação da figura jurídica intitulada "estado de coisas inconstitucional", desde sua declaração, pela primeira vez, em uma sentença da Corte Constitucional colombiana até o seu ingresso na jurisprudência brasileira, percebeu-se que se trata de uma figura jurisprudencial em construção, que ainda deverá ser objeto de inúmeras discussões e pesquisas acadêmicas.

O presente trabalho se propôs a oferecer alguma contribuição para a ampliação do âmbito de aplicação desse conceito ao confrontá-lo com um tema em que essa figura ainda não veio considerada pela jurisprudência do STF, mas que se revelou muito profícuo para repensar

\footnotetext{
${ }^{44} \mathrm{O}$ quadro demonstrativo com essas informações foi trazido pelo ministro relator como forma de avaliação do impacto orçamentário de uma eventual mudança de critério. Para mais informações, cfr. BRASIL. Supremo Tribunal Federal. Reclamação 4.374. 2013, p. 40.
}

Rev. do Cejur: Prestação Jurisdicional, Florianópolis v.7 n.1, p. 219-237, Janeiro-Dezembro. 2019. 
uma decisão da própria corte. Não se tratou, aqui, da importação acrítica e irrefletida de uma categoria estrangeira, mas da discussão meditada sobre uma solução viável a problemas sociais internos levando em conta as suas especificidades e a sua adequação ao caso concreto.

Por certo, compreende-se as limitações desse tipo de exercício, pois recorrer a essa figura jurídica - endereçada a garantir a dimensão objetiva dos direitos fundamentais - significa admitir a existência de um juiz particularmente crítico com o funcionamento da administração pública, que até mesmo condena o Estado a implantar políticas públicas em casos de extrema gravidade estrutural. Isso porque, em cenários de falhas estruturais e omissões legislativas e administrativas, a atuação ativista do Judiciário acaba por ser o único meio de superar esses desacordos políticos e institucionais.

Neste artigo, como já ressaltado, trabalhou-se com a ideia de ativismo judicial estrutural dialógico, de modo que essa intervenção só se considera legítima quando baseada em uma postura de diálogo por parte da autoridade judiciária, que não se coloca em posição de supremacia perante as demais instituições a que são dirigidas as suas recomendações para mudança de políticas públicas. Com a ideia de diálogo, entretanto, não se quer enfraquecer o caráter vinculativo das indicações estabelecidas pela corte, tendo em vista que a dramaticidade e a complexidade das questões que envolvem o reconhecimento do ECI requerem medidas concretas e céleres.

Por mais que se tenha proposto, no presente estudo, a ampliação e aplicação desse conceito para uma discussão em que até então essa categoria jurídica não havia sido pensada, reconhece-se que ela deva ser adotada com cautela, primando pela interação institucional conjunta em prol de um objetivo comum.

O escopo maior é a concretização da constituição como um todo, não de preceitos constitucionais particulares, reconhecendo que a violação de determinados direitos sociais e a proteção deficiente por parte do Estado acaba gerando um quadro de inconstitucionalidade grave que vulnerabiliza, ainda mais, grupos sociais que se encontram em situações de miserabilidade social.

Por fim, reforça-se que o compromisso último do Estado democrático de direito deve ser com a efetividade dos direitos fundamentais e todos as reflexões aqui propostas voltam-se a esse objetivo, devendo ser também esta a direção de orientação de todas as políticas públicas e da atuação conjunta e dialógica dos três poderes da República. 


\section{REFERÊNCIAS}

BRASIL. Constituição (1988). Constituição da República Federativa do Brasil. Distrito Federal, $\quad$ SC, 5 out. $1988 . \quad$ Disponível em: <http://www.planalto.gov.br/ccivil_03/constituicao/constituicao.htm>. Acesso em: 20 de julho de 2017.

Dispõe sobre a organização da Assistência Social e dá outras providências.. Lei $\mathbf{N}^{\mathbf{o}}$ 8.742, de 7 de Dezembro de 1993. Brasília, DF, 7 dez. 1993. Disponível em: <http://www.planalto.gov.br/ccivil_03/leis/L8742.htm>. Acesso em: 20 de julho de 2017.

Supremo Tribunal Federal. Ação Direta de Inconstitucionalidade n. 1232-1/DF. Relator: Ministro Nelson Jobim. Brasília, DF, 27 de agosto de 1998. Diário da Justiça. Brasília, 27 ago. $1998 . \quad$ Disponível $<$ http://redir.stf.jus.br/paginadorpub/paginador.jsp?docTP=AC\&docID=385451 >. Acesso em: 21 de julho de 2017.

. Supremo Tribunal Federal. Arguição de Descumprimento de Preceito Fundamental n. 347. Relator: Ministro Marco Aurélio. Brasília, DF, 9 de setembro de 2015. Diário da Justiça. Brasília, 9 set. $92015 . \quad$ Disponível em: http://redir.stf.jus.br/paginadorpub/paginador.jsp?docTP=TP\&docID=10300665>. Acesso em: 21 de julho de 2017.

Supremo Tribunal Federal. Habeas Corpus 118.533/MS. Relator: Ministra Carmen Lúcia. Brasília, DF, 23 de junho de 2016. Diário da Justiça. Brasília, 23 jun. 2016. Disponível em: $\quad$ http://redir.stf.jus.br/paginadorpub/paginador.jsp?docTP=TP\&docID=11677998>. Acesso em: 21 de julho de 2017.

Supremo Tribunal Federal. Reclamação 4.374. Relator: Ministro Gilmar Mendes. Brasília, DF, 18 de abril de 2013. Diário da Justiça, Brasília, 18 abr. de 2013. Disponível em: $<$ http://redir.stf.jus.br/paginadorpub/paginador.jsp?docTP=TP\&docID=4439489>. Acesso em: 21 de julho de 2017.

Supremo Tribunal Federal. Recurso Extraordinário 641.320. Relator: Ministro Gilmar Mendes. Brasília, DF, 11 de maio de 2016. Diário da Justiça. Brasília, 11 mai. 2016. Disponível

em: $<$ http://redir.stf.jus.br/paginadorpub/paginador.jsp?docTP=TP\&docID=11436372>. Acesso em: 21 de julho de 2017.

Supremo Tribunal Federal. Recurso Extraordinário 841.526. Relator: Ministro Luix Fux. Brasília, DF, 30 de março de 2016. Diário da Justiça. Brasília, 30 mar. 2016. Disponível em: $\quad$ <ttp://redir.stf.jus.br/paginadorpub/paginador.jsp?docTP=TP\&docID=11428494>. Acesso em: 21 de julho de 2017.

BROOCKE, Alexandre Moreira van Der. A proibição de proteção deficiente e a inconstitucionalidade do artigo 20 da lei n. 8.429/1991. Revista da Ajuris: Associação dos Juízes do Rio Grande do Sul, Porto Alegre, v. 40, n. 129, p.13-136, 2013. 
CAMPOS, Carlos Alexandre de Azevedo. Dimensões do ativismo judicial do STF. Rio de janeiro: Forense, 2014.

Estado de coisas Inconstitucional. Salvador: JusPodium, 2016.

CANOTILHO. José Joaquim Gomes. Direito Constitucional e Teoria da Constituição. $7^{\mathrm{a}}$ ed. Coimbra: Alamedina, 1997.

COLÔMBIA. Corte Constitucional. Sentencia Unificadora $\mathrm{n}^{\circ}$ 090/00. Relator: Eduardo Cifiuentes Muñoz. Diario Oficial. Bogotá, 2 fev. 2000. Disponível em: <http://www.corteconstitucional.gov.co/RELATORIA/2000/SU090-00.htm>. Acesso em: 20 de julho de 2017.

Corte Constitucional. Sentencia Unificadora $n^{\circ}$ 559/97. Relator: Eduardo Cifiuentes Muñoz. Diario Oficial. Bogotá, 5 nov. 1997. Disponível em: <http://www.corteconstitucional.gov.co/RELATORIA/1997/SU559-97.htm>. Acesso em: 20 de julho de 2017.

Corte Constitucional. Sentencia T-068/10. Relator: Ignacio Pretelt Chaljub. Diario

Oficial. Bogotá, 4 fev. 2010. Disponível em: <http://www.corteconstitucional.gov.co/RELATORIA/2010/T-068-10.htm>. Acesso em: 20 de julho de 2017.

Corte Constitucional. Sentencia T-1030. Relatora: Clara Inés Vargas Hernández. Diario Oficial. Bogotá, 30 out. 2003. Disponível em: <http://www.corteconstitucional.gov.co/relatoria/2003/t-1030-03.htm>. Acesso em: 20 de julho de 2017.

CONECTAS. STF em foco. 2017. Disponível em: <http://www.conectas.org/pt/acoes/stf-emfoco>. Acesso em: 19 de julho de 2017.

CONSELHO NACIONAL DE JUSTIÇA. Supremo em Ação. 2017. Disponível em: <http://www.cnj.jus.br/pesquisas-judiciarias/supremo-em-acao>. Acesso em: 19 de julho de 2017.

CONTRERAS, Edgar Hernán Fuentes; LÓPEZ, Beatriz Eugenia Suárez; VILLEGAS, Adriana Rincón. Facticidad y Constitución: la doctrina del estado de cosas inconstitucional en América Latina. Athenas, Conselheiro Lafaiete, v. 1, n. 2, p.49-75, jul. 2012.

FUNDAÇÃO GETÚLIO VARGAS. Supremo em números. 2017. Disponível em: <http://www.fgv.br/supremoemnumeros/sobre.html>. Acesso em: 20 de julho de 2017.

Supremo em pauta. 2017. Disponível em: <http://direitosp.fgv.br/supremoempauta> . Acesso em: 20 jul. 2017.

HERNÁNDEZ, Clara Inés Vargas. La Garantía de la dimensión objetiva de los derechos fundamentales y labor del juez constitucional colombiano em sede de acción de tutela: el llamado "estado de cosas inconstitucional". Revista del Centro de Estudios Constitucionales, Santiago, v. 1, n. 1, p. 203-228, 2003. 
KMIEC, Keenan D. The Origin and Current Meaning of "Judicial Activism". California Law Review, v. 92, n. 5, 2004, p. 1441-1477. Disponível em: <http://scholarship.law.berkeley.edu/cgi/viewcontent.cgi?article=1324\&context=californiala wreview>. Acesso em: 20 de julho de 2017.

MARTÍNEZ, Julián Tole. La teoria de la doble dimensión de los derechos fundamentales en Colombia.: El estado de cosas inconstitucionales, un ejemplo de su aplicación.. Cuestiones Constitucionales, Cidade do México, v. 15, n. 2, p.253-316, jun. 2006. Disponível em: <http://www.redalyc.org/articulo.oa?id=88501510>. Acesso em: 23 jul. 2017.

MENDES, Conrado Hübner. Direitos fundamentais, separação de poderes e deliberação. Saraiva: São Paulo, 2011.

SILVA, José Afonso. Aplicabilidade das Normas Constitucionais. $3^{\text {a }}$ ed. São Paulo: Malheiros, 1998.

TASSINARI, Clarissa. Ativismo Judicial: Uma análise da atuação do Judiciário nas experiências brasileira e norte-americana. 2012. 139 f. Dissertação (Mestrado) - Curso de Direito, Universidade do Vale do Rio Sinos, São Leopoldo, 2012.

TORRES, Ricardo Lobo. A metamorfose dos direitos sociais em mínimo existencial. In: SARLET, Ingo Wolfgang. Direitos Fundamentais Sociais: estudos de direito constitucional, internacional e comparado. Rio de Janeiro: Renovar, 2003, p. 1-46. 